\title{
Un Maestro de América
}

T a prueba de fuego para el escritor, por lo menos, para cierta clase de escritores, es la proximidad, la viva e inmediata convivencia con el lector. Sin duda, para ciertas especies de producción intelectual, la cercanía y trato con el autor no quita ni agrega nada, porque cuanto solicitamos de él nos lo proporciona su obra, y si luego nós aproximamos a la persona o buscamos información sobre ella, no es para corroborar la enjundia del escrito, sino únicamente por un sentimiento de simpatía humana o por un movimiento de curiosidad. Pero no ocurre así en otros casos. Cuando la obra no es de índole puramente estética o fríamente científica; cuando tiene algo de mensaje; cuando lo intelectual se acompaña de una resonancia cordial o ética, entonces nos parece que la enseñanza del papel impreso se completa y perfecciona con la presencia del autor, con la visión de su rostro y el sonido de su voz y sus ademanes y gestos. Es como si pidiésemos al hombre la confirmación de lo que de él leímos, como si buscarámos en la persona téstimonio y garantía de la obra, dispuestos a conceder a ésta el crédito que la persona nos merezca. Esta experiencia de repensar una enseñanza bebida en la lectura, en la presencia actual del autor y a veces a lo largo de alguna convivencia con él -experiencia tantas veces decepcionante- la tuve yo con don Baldomero Sanín Cano hace ya bastantes años, en Buenos Aires. Don Baldomero, residente por entonces en nuestra ciudad, frecuentaba ciertos grupos de que yo formaba parte $y$ en los cuales era costumbre el encuentro, hasta regularmente semanal en algunos casos. Sanín Cano llevaba a estas largas conversaciones ese saber madurado en sabiduría que sólo poseen los que han decantado los zumos de la vida y de los libros en los senos de una conciencia lúcida y profunda. Su palabra era escuchada con respeto, 
y él tenía el arte de saber escuchar a los demás. Suscitaba por igual la admiración y el cariño, y cuando, alejado de Buenos Aires, nos faltó su compañía, nos parecía sentirlo de continuo entre nosotros, y sólo así nos consolábamos de no tenerlo a nuestro lado. Yo sé que este trato con Sanín Cano ha engendrado con él muchas amistades de esas que desafían luego el tiempo y la distancia, y se preservan y cultivan como bienes inapreciables. Seguro y afable, firme en sus convicciones y tolerante con las ajenas, docto en todo saber y en la ciencia de la vida, ya la primera impresión que proporcionaba al conocerlo era la del indiscutible maestro que ha sido desde bien temprano.

Sanín Cano encarna con perfección un tipo intelectual que es acaso el que más escasea en nuestras tierras y probablemente el que más necesitamos. En Hispanoamérica abundan los especialistas capaces de examinar con rigor y versación un problema histórico, filosófico y aun científico; abundan también los puros literarios, muchas veces de calidad notable. En cambio escasean los ensayistas, los que podríamos denominar los hombres de las ideas en libertad. $Y$ no andaríamos muy lejos de la verdad si dijéramos que es Sanín Cano nuestro ensayista máximo, entre los vivientes. El ensayista es uno de los más refinados y complejos productos de una culturta, y por eso la nuestra, todavía juvenil, cuando no puerilmente escolar, nos los ofrece con tan lamentable rareza. En otras formas de la actividad del ánimo, la imitación y la importación de lo ajeno suplen la carencia de lo propio; el ensayista no puede ser imitador ni le es lícita la importación lisa y llana de lo extraño, por el personalísimo cariz de su profesión, que tiene tanto del arte como de la ciencia, pero que es, sobre todo, la expresión de una individualidad espiritual. Es fácil, hasta donde puede calificarse de fácil la honrada tarea intelectual, producir ateniéndose a los cauces preexistentes de la indagación o exposición histórica, filosófica o científica; en ellas se puede realizar una faena útil y meritoria, aun cuando no se posea un talento eminente. El tratadista de esos asuntos se subordina a los objetos de su interés, sea de primera, sea de segunda mano, y nos brinda sus resultados propios o nos comunica los ajenos con lo cual en toda circunstancia vamos ganando algo o mucho E1 ensayista representa otro género de enfoque y de preocupación. Su personalidad predomina sobre su așunto; lo humano le interesa antes 
que lo especial. Cada particular tema, aunque por ventura lo domine y ahonde como el especialista más consumado, es para él un momento o accidente en el vasto paisaje de la vida y de la cultura. Nunca se deja absorber por el asunto, hasta el extremo de olvidar que es un episodio en el desfile de las horas y de los sucesos. La totalidad del panorama intelectual es su experiencia dominante, y esa experiencia se concentra y vibra en un alma abierta a todos los vientos del espíritu, alerta a todos los ecos y rumores, exploradora de todos los rumbos de la cultura, rica en conocimiento y más rica todavía en comprensión. El ensayista, cuando lo es genuinamente, es el gran señor de la cultura, ese aristócrata cuya multiplicación es la condición necesaria para cualquier democracia auténtica: no en vano ni casualmente coinciden en Inglaterra el ensayismo y la democracia, con arraigo y solidez incomparables. El especialista se ciñe a su tema y en cierta medida le sacrifica su autonomía; hasta en ocasiones, para ser buen especialista, para rendir su máximo esfuerzo, tiene que autolimitarse y deshumanizarse, tiene que llegar a ser tan circunscrito a un punto como el obrero de la gran industria que sólo realiza, infinitamente repetida, una sola operación ínfima. Es habitual que desconozca cuanto no toca a su oficio y aunque desprecie todo el restante ámbito cultural, si bien suele enmascarar su desestima con las apariencias de un aprecio tolerante. E1 ensayista reivindica al hombre ante la imponente masa de los bienes de la civilización; en forma palpable muestra que toda actividad y todo producto cultural brotan del hombre y son para el hombre, componen un orbe del cual el hombre es el motor, el centro y el fin. Hasta podría decirse que el ensayista encarna el espiritu filosófico con mayor fidelidad que el filósofo mismo, porque el filósofo, agente de la tendencia a lo universal, llega a convertirse en un especialista de ese universal que persigue, cuyas manifestaciones concretas y palpitantes, por lo tanto, se le esconden. Representa, pues, el ensayista, como antes se dijo, el espíritu en libertad. La característica del ensayismo es la primacía del autor sobre su tema, pero no como libérrima arbitrariedad o capricho irresponsable, sino como la supeditación de cada asunto o tema parcial a una amplísima experiencia humana, que lo sitúa en un tejido de innumerables correlaciones expresas o tácitas, en un campo poblado de incontables ecos. $\mathrm{Y}$ de este modo, cualquier asunto se renueva entre las manos del ensayista, 
cobra una vida nueva y fecunda, porque todo lo demás concurre a fertilizarlo, y él a su vez fertiliza todo lo demás. El secreto del cumplido ensayista consiste en contar, mucho más allá de su tema ocasional, en sus aledaños y aun en el interior del tema mismo, con todo lo restante; lo cual viene a ser una manera de poner al tema en función del hombre, ya que es condición natural del hombre ser el foco y punto de referencia de todo lo habido y por haber. En realidad, es éste uno de los principales requisitos del pensamiento filosófico: pensar en una cosa, pensando al mismo tiempo en todo lo demás; lograr que el conjunto sirva de contorno y acompañamiento a cada particular motivo. Pero ya se ha dicho que el ensayista, desde cierto punto de mira, asume una posición más filosófica que la del filósofo profesional, constreñido por propensión y oficio a derivar hacia el especialismo y a naufragar finalmente en él.

Ensayista ejemplar, la cultura colombiana ha tenido en Sanín Cano un guía seguro y con frecuencia un adelantado que ha sabido incorporarle tempranamente muchas puras esencias de la cultura universal. Maestro americano, no podría ser él sino maestro en universalismo, porque la universalidad es una de las vocaciones de nuestra América, y no hay razón para que no conviva con la peculiaridad nacional y aun local y hasta se asiente en ella, como no hay inconveniente para que una misma verdad sea pronunciada en muy diversos idiomas. La contraposición de lo propio a lo que es, por su índole y su alcance, de todos, es una de las torpezas que debemos combatir, una de las falsas oposiciones que no engendran sino confusiones y valoraciones absurdas, y cuya única consecuencia a la larga es el gasto inútil de energías y la pérdida de tiempo, porque todo lo altamente humano es de todo hombre por derecho intrínseco y termina por ser reconocido así, mientras los prejuicios lugareños caen desvanecidos, más que por cualquier crítica, por la muerte que llevan dentro, por la propia inanidad.

Sanín Cano ha sido fiel a su patria nacional y a su más extensa patria americana, siendo fiel a la cultura de occidente. Este homenaje tardaba ya. Muchas veces sus amigos hemos reparado en el débito que con él se tiene, en la deuda de América hacia uno de sus hijos más preclaros por la inteligencia, la rectitud y el servicio; que es como si dijéramos: por el aporte y por el ejemplo. Todavía nuestros varones de jerarquía más excelsa no han obtenido el recono- 
cimiento que merecen en la conciencia común, ni la justa ponderación de sus valores en estudios que aquilaten sus méritos y diluciden la magnitud de sus contribuciones: obligaciones que de ninguna manera son exclusivas de los respectivos países para con sus nacionales, porque nuestra cultura salva fronteras y es tesoro indiviso de toda el área iberoamericana, y, con determinadas reservas y restricciones, también de todo el continente, cuya solidaridad material y espiritual comprenden mejor cada día los más avisados. Uno de nuestros deberes de urgencia es el recuento y destaque de nuestras fuerzas válidas, de los impulsos civilizadores con que contamos, de los elementos que poseemos para la elevación de la vida en nuestros países; entre estos elementos, huelga decirlo, los primeros y capitales son esos hombres de excepción que honran a toda América, sea la que fuere la parcela americana a que por su origen pertenezcan. Si les debemos su acción, todos nos debemos a nosotros mismos procurar que esa acción se difunda, se estime, se aproveche. Ante el caso concreto de don Baldomero Sanín Cano esta obligación se refuerza particularmente, pues personifica él uno de los más nobles y eficaces estímulos con que ha contado y cuenta la espiritualidad de nuestras tierras.

Francisco Romero, Martinez, Buenos Aires. 
